\title{
Characteristics of Patient with Proliferative Diabetic Retinopathy Underwent Anti-Vascular Endothelial Growth Factors Injection in Cicendo Eye Hospital, Bandung in January-December 2013
}

\author{
Marsha Rayfa Pintary, ${ }^{1}$ Arief S. Kartasasmita, ${ }^{2}$ Juliati $^{3}$ \\ ${ }^{1}$ Faculty of Medicine Universitas Padjadjaran, ${ }^{2}$ Department of Ophthalmology Faculty of Medicine \\ Universitas Padjadjaran/Cicendo Eye Hospital, Bandung, ${ }^{3}$ Department of Physiology Faculty of \\ Medicine Universitas Padjadjaran
}

\begin{abstract}
Background: Proliferative Diabetic Retinopathy (DR) is one of the microvascular complications of diabetes mellitus (DM) that is prevalent to the blindness risk. The World Health Organization (WHO) considers Proliferative DR one of the priorities of eye diseases. This disease is caused by angiogenesis brought about by Vascular Endothelial Growth Factors (VEGF). The Anti-VEGF Bevacizumab (Avastin) injection is considered sufficient in preventing proliferative DR patients from blindness. This study aimed to identify the characteristics of patients with proliferative DR underwent Anti-VEGF injection at Cicendo Eye Hospital, Bandung.

Methods: This was a retrospective study conducted from August-October 2014 using 40 medical records of patients with proliferative DR underwent Anti-VEGF Bevacizumab (Avastin) injection at the Cicendo Eye Hospital Bandung from January-December 2013. Inclusion criteria were the patients underwent anti-VEGF injection with complete medical records with minimum follow up of 3 weeks.

Results: Among 40 patients, 55\% were male and 45\% were female. Furthermore, there was $100 \%$ found for DM Type 2. Moreover, random blood glucose varied among 140-200mg/dl (50\%), while the hypertension was mostly at stage 2 . Some of these patients had proliferative DR with vitreal hemorrhage (25\%), macular edema (40\%), and/or tractionalablasio retina (22.5\%). Most patients had an improvement in their visual acuity $(60 \%)$.

Conclusions: Most of patients are male, aged 50-59 years old, random blood glucose among 140$200 \mathrm{mg} / \mathrm{dl}$, followed DM Type 2 and hypertension stage 2. Anti-VEGF injection improves visual acuity. [AM],2016;3(2):280-5]
\end{abstract}

Keywords: Anti-VEGF, bevacizumab, proliferative diabetic retinopathy

\section{Introduction}

Diabetes Mellitus (DM) is a chronic disease involving carbohydrates, lipid and protein metabolisms in the body. This chronic lifelong disease can lead to severe complications and even death. ${ }^{1}$ The global incidence of DM continues to spike up. Indonesia is anticipated to be among the top 30 countries with high number of diabetes patients in the year $2030 .^{2}$ The increasing cases of microvascular complications such as diabetic retinopathy (DR) corresponds with the increase of DM cases. ${ }^{3}$ The DR is a progressive degenerating disease of the retina and one of the main causes of blindness in the world especially in adults aged 20-74 years old in the developing countries. ${ }^{2,4}$ The World Health Organization (WHO) has taken prompt action in tackling this serious matter and included it into their program, Vision 2020 the right to sight. ${ }^{3}$

Proliferative DR is a severe complication which jeopardizes the eyesight which usually occurs during angiogenesis or formation of new pathologic blood vessels. ${ }^{5}$ It usually results from high level of vascular endothelial growth factor (VEGF) in blood vessels. ${ }^{6}$ Proliferative DR leads to its complications such as vitreous hemorrhage, tractional retinal detachment, and blindness if it is untreated. Panretinal photocoagulation (PRP), the gold standard treatment for proliferative DR takes a long time for neovascular regression and high risk in complications. ${ }^{5}$ In 2005, it was discovered

Correspondence: Marsha Rayfa Pintary, Faculty of Medicine, Universitas Padjadjaran, Jalan Raya Bandung-Sumedang Km.21, Jatinangor, Sumedang, Indonesia, Phone: +62 82126982505 Email: marsharayfa@icloud.com 
that a safe and effective treatment becoming a trend in the world of ophthalmology is regressing vascular by injecting anti-VEGF in the retina, one of them is bevacizumab (Avastin; Genentech, Inc, South San Francisco, California, USA). ${ }^{7}$ Bevacizumab was initially used to treat colorectal cancer but now it is used off-label to treat eye diseases including proliferative DR.6 On a separate matter, bevacizumab has been shown to speed up neovascular regeneration and decrease macular edema in DR in previous studies.5,8 In addition to its low cost and repetitive usage, bevacizumab is able to prevent systemic complications by local application in low dosage.5,9 Unfortunately, intravitreal anti-VEGF injection increases the risk for endophthalmitis and retinal detachment in DM patients.10 In Indonesia, there are no sound data regarding the characteristics of post injection antiVEGF in patient with Proliferative DR. On the other hand, there are many published study regarding the efficacy of this treatment. Given these facts, this study was aimed to identify the characteristics of post injection anti-VEGF in patient with proliferative DR at Cicendo Eye Hospital, Bandung.

\section{Methods}

A quantitative descriptive study was conducted from August-October 2014 using retrospective method in Cicendo Eye Hospital, Bandung. The Health Research Ethics Committee Faculty of Medicine, Universitas Padjadjaran had approved this study. The population was the patients with proliferative DR who underwent anti-VEGF injection operation in Cicendo Eye Hospital, Bandung in the period of January to December 2013. The sample was selected using the total sampling.

Out of 490 patients with DR, 40 patients were included as samples in this study. The sample was selected from the medical record with certain inclusion and exclusion criteria. Inclusion criteria includes all patients underwent anti-VEGF injection with complete medical records with minimum follow up of 3 weeks while the exclusion criteria were all patients with medical records that do not contain data postoperative of anti-VEGF injection.

In this study, gender, age, types of DM, diagnosis, presence of macular edema, presence of tractional retinal detachment, vitreal hemorrhage, random blood glucose levels, blood pressure, frequency of anti-VEGF injection, vision acuity before and after the operation, and post operation complication were also collected. Random blood glucose levels were then divided into 3 categories; $<140$ $\mathrm{mg} / \mathrm{dl}, 140-200 \mathrm{mg} / \mathrm{dl},>200 \mathrm{mg} / \mathrm{dl}$. Blood pressure was also categorized into Normal $(<120 /<80 \mathrm{mmHg})$, Prehypertension (120-

Table 1 1Demography Characteristic of Patients

\begin{tabular}{|c|c|c|}
\hline Characteristic & Number of Patients (n) & $\%$ \\
\hline \multicolumn{3}{|l|}{ Gender } \\
\hline Male & 22 & 55 \\
\hline Female & 18 & 45 \\
\hline \multicolumn{3}{|l|}{ Age (years old) } \\
\hline $40-49$ & 9 & 22.5 \\
\hline $50-59$ & 20 & 50 \\
\hline $60-69$ & 11 & 27.5 \\
\hline \multicolumn{3}{|l|}{ Type of DM } \\
\hline DM Type 1 & 0 & 0 \\
\hline DM Type 2 & 40 & 100 \\
\hline \multicolumn{3}{|l|}{ Duration of DM } \\
\hline$<5$ years & 8 & 20 \\
\hline $5-10$ years & 14 & 35 \\
\hline$>10$ years & 18 & 45 \\
\hline
\end{tabular}

Note: DM: Diabetes Mellitus 
Table 2 Clinical Status of Patients

\begin{tabular}{|c|c|c|}
\hline Characteristic & Number of Patients (n) & $\%$ \\
\hline \multicolumn{3}{|l|}{ Random Blood Glucose } \\
\hline$<140 \mathrm{mg} / \mathrm{dl}$ & 18 & 45 \\
\hline $140-200 \mathrm{mg} / \mathrm{dl}$ & 20 & 50 \\
\hline$>200 \mathrm{mg} / \mathrm{dl}$ & 2 & 5 \\
\hline \multicolumn{3}{|l|}{ Blood Pressure } \\
\hline Normotension & 5 & 12.5 \\
\hline Prehypertension & 5 & 12.5 \\
\hline Hypertension Stage 1 & 14 & 35 \\
\hline Hypertension Stage 2 & 16 & 40 \\
\hline \multicolumn{3}{|l|}{ Eyes Affected } \\
\hline Ocular Dextra (OD) & 22 & 55 \\
\hline Ocular Sinistra (OS) & 18 & 45 \\
\hline \multicolumn{3}{|l|}{ Diagnosis } \\
\hline Preproliferative DR & 16 & 40 \\
\hline Proliferative DR & 24 & 60 \\
\hline \multicolumn{3}{|l|}{ Vitreous Hemorrhage } \\
\hline Yes & 10 & 25 \\
\hline No & 30 & 75 \\
\hline \multicolumn{3}{|l|}{ Macular Edema } \\
\hline Yes & 16 & 40 \\
\hline No & 24 & 60 \\
\hline \multicolumn{3}{|l|}{ Tractional Retinal Detachment } \\
\hline Yes & 9 & 22.5 \\
\hline No & 31 & 77.5 \\
\hline
\end{tabular}

Note: DR: Diabetic Retinopathy

139/80-89mmHg), Stage 1 Hypertension (140-159/90-99mmHg), and Stage 2 Hypertension $(>160 />100 \mathrm{mmHg}$ ) based on JNC 7. Visual acuity was categorized based on WHO Blindness Classification, Normal (V/A 6/6-6/18-), Visual Impairment (V/A 6/18$6 / 60$ ), Severe Visual Impairment (V/A $<6 / 60-$ $3 / 60$ ) and Blind (V/A $<3 / 60-N P L)$. Data were analyzed using computer and presented in table.

\section{Results}

From 40 patients, the majority of the patients were male $(55 \%)$ which $>40$ years old with the highest range of age between 50-59 years old. There was no patient with DM type 1 and the average duration of DM was about $>10$ years. The number of patients with proliferative DR increased in accordance with the duration of DM (Table 1).

Based on the clinical status, most patients had the blood glucose levels around 140$200 \mathrm{mg} / \mathrm{dl} \mathrm{(50 \% ),} \mathrm{while} \mathrm{the} \mathrm{majority} \mathrm{of}$ hypertension was at stage 2. Anti-VEGF injection was given mostly to the right eye (55\%). The majority of the patients were confirmed to have proliferative DR (60\%) while those with preproliferative DR were only $40 \%$. In a small number of patients, 10 people (25\%) experienced vitreous hemorrhage, 16 people $(40 \%)$ had macular edema and 9 people $(22.5 \%)$ had tractional retinal detachment (Table 2).

There were about 20 patients (50\%) experienced blindness after the treatment. Most of these patients (34\%), received only single anti-VEGF Avastin. On the other hand, most patients experienced improvement in 
Marsha Rayfa Pintary, Arief S. Kartasasmita, Juliati: Characteristics of Patient with Proliferative Diabetic

Table 3 Clinical Status of Patients

\begin{tabular}{lcc}
\hline \multicolumn{1}{c}{ Characteristic } & Number of Patients (n) & \% \\
\hline Visual Acuity Pre Injection & 6 & 15 \\
Normal & 3 & 7.5 \\
Visual Impairment & 11 & 27.5 \\
Severe Visual Impairment & 20 & 50 \\
Blind & & 60 \\
Visual Acuity Post Injection & 24 & 25 \\
Increase & 10 & 15 \\
Not Improved & 6 & 85 \\
Decrease & & 10 \\
Frequency of Injection & 34 & 5 \\
$1 \mathrm{x}$ & 4 & 2.5 \\
$2 \mathrm{x}$ & 2 & 97.5 \\
$3 \mathrm{x}$ & & \\
Complication & 1 & \\
Yes & 39 & \\
No & & \\
\hline
\end{tabular}

their vision after treatment (15\%). However, there was one complicated case in which the patient got infected and bleeding (Table 3).

\section{Discussion}

There were 22 male patients and 18 female patients involved in this study. The total number of patients did not align with the actual general prevalence of proliferative DR which states females are more prone to proliferative DR compared to males. This was due to several factors, including low awareness, financial problems, limited access to health care, and mainly the insufficiency of time which leads to the attempt of acquiring knowledge and doing socialization regarding the diabetic retinopathy by the health providers in primary care. ${ }^{11}$

The examined patients were above 40 years old. A study conducted in the United States of America $^{12}$ found that diabetic patients aged above 40 years old have higher prevalence of getting DR which would threaten their eyesight. This study shows that the highest number of patients with DR is dominated by patients aged 50-59 years old while patients above 60 years old are fewer. This could be due to the fact that DM is a degenerative disease and as it progresses, severe complications will occur which ultimately lead to death. ${ }^{13}$
In this study, DM type 2 was predominant and this corresponded to the fact that $90-95 \%$ of DM patients usually have type $2 \mathrm{DM}^{14}{ }^{14} \mathrm{In}$ addition, as shown in other studies, DM type 2 is dominant in Asia compared to DM type $1 .^{15}$

The duration of DM is a major risk factor for the occurrence of DR. The longer duration of DM, the higher the prevalence of DR in DM type $2 .{ }^{16}$ It was found that $45 \%$ of the patients have been experiencing DM for more than 10 years.

Severe hyperglycemia is the contributing key for DR and it can be prevented by controlling one's blood glucose. ${ }^{14}$ It is crucial to control blood glucose level prior to surgery as it can delay the progression of the disease and decrease complications. ${ }^{14,16}$ Half of the patients have blood glucose levels between $140-200 \mathrm{mg} / \mathrm{dl}$ and only $5 \%$ of them have blood glucose levels above $200 \mathrm{mg} / \mathrm{dl}$. These patients are expected to have better outcomes. As stated earlier, patients with low blood glucose are expected to have better outcomes as hyperglycemia is the key to DR. ${ }^{17}$ On the other hand, most of the patients have hypertension stage 2 because they neglected the blood pressure control. Strict control of blood pressure $(<130 / 80 \mathrm{mmHg})$ has been shown to decrease the risk of blindness. Furthermore, the risk of DR decreases by 10$13 \%$ for every reduction in $10 \mathrm{mmHg}$ of blood pressure. $^{14}$ 
Based on the data obtained, most patients have PDR $(60 \%)$ while the rest have preproliferative DR. Moreover, it was found that some patients suffer from vitreous hemorrhage (25\%), macular edema $(40 \%)$, and tractional retinal detachment $(22.5 \%)$ while some patients (50\%) are found to be blind after visual acuity examination. Blindness among DM patients normally is because of under-detection of DR at an early stage. In a previous study, DR has been shown to be under-detected among DM patients. ${ }^{18}$ The patients should be encouraged to routine their eye examination preventive care to avoid undesirable outcome. Moreover, studies in Australia $^{19}$ and Spain ${ }^{20}$ clearly showed that primary healthcare doctors are sufficient to help decreasing the prevalence of DR among patients with DM provided with adequate training. It is recommended for official guidelines to be published in Indonesia and adequate training should be provided to primary health care providers in order to tackle this issue effectively.

The limitation of this study was the improvement of visual acuity did not classify based on pre injection examination, that make it difficult to determine which group has significant improvement after the treatment.

In conclusion, this study shows that the number of male patients is higher than female. These patients mostly aged 50-59 years old, random blood glucose among 140-200mg/ $\mathrm{dl}$, suffer from DM Type 2 and hypertension stage 2. This study also found that Anti-VEGF injection improves visual acuity.

For further studies, it is recommended to use prospective design and classify the result of visual acuity before the treatment.

\section{References}

1. Suyono S. Diabetes melitus di Indonesia. In: Sudoyo AW, Setiyohadi B, Alwi I, Simadibrata M, Setiati S, editors. Buku ajar ilmu penyakit dalam. 5th ed. Jakarta: Interna Publishing, Pusat Penerbitan Ilmu Penyakit Dalam Fakultas Kedokteran Universitas Indonesia; 2009

2. Wild SH, Roglic G, Green A, Sicree R, King H. Global prevalence of diabetes: estimates for the year 2000 and projections for 2030 response to Rathman and Giani. Diabetes Care. 2004;27(10):2568-9.

3. Wang X, Wang G, Wang Y. Intravitreous vascular endothelial growth factor and hypoxia-inducible factor $1 \mathrm{a}$ in patients with proliferative diabetic retinopathy. Am
J Ophthalmol. 2009;148(6):883-9.

4. Pai A, El Shafei MM, Mohammed OA, Al Hashimi M. Current concepts in intravitreal drug therapy for diabetic retinopathy. Saudi J Ophthalmol. 2010;24(4):143-9.

5. Ma Y, Zhang Y, Zhao T, Jiang Y-r. Vascular endothelial growth factor in plasma and vitreous fluid of patients with proliferative diabetic retinopathy patients after intravitreal injection of bevacizumab. Am J Ophthalmol. 2012;153(2):307-13.e2.

6. Kohno R-I, Hata Y, Mochizuki Y, Arita R, Kawahara S, Kita T, et al. Histopathology of neovascular tissue from eyes with proliferative diabetic retinopathy after intravitreal bevacizumab injection. Am J Ophthalmol. 2010;150(2):223-9.e1.

7. Gunther JB, Altaweel MM. Bevacizumab (Avastin) for the treatmentofoculardisease. Surv Ophthalmol. 2009;54(3):372-400.

8. Waisbourd M, Goldstein M, Loewenstein A. Treatment of diabetic retinopathy with anti-VEGF drugs. Acta Ophthalmol. 2011;89(3):203-7.

9. Raftery J, Clegg A, Jones J, Tan SC, Lotery A. Ranibizumab (Lucentis) versus bevacizumab (Avastin): modelling cost effectiveness. $\mathrm{Br} \mathrm{J}$ Ophthalmol. 2007;91(9):1244-6.

10. Simó R, Hernández C. Intravitreous antiVEGF for diabetic retinopathy: hopes and fears for a new therapeutic strategy. Diabetologia. 2008;51(9):1574-80.

11. Munoz B, O'Leary M, Fonseca-Becker F, Rosario E, Burguess I, Aguilar M, et al. Knowledge of diabetic eye disease and vision care guidelines among Hispanic individuals in Baltimore with and without diabetes. Archophthalmol. 2008;126(7):968-74.

12. Falcão M, Falcão-Reis F, Rocha-Sousa A. Diabetic retinopathy: understanding pathologic angiogenesis and exploring its treatment options. The Open Circulation and Vascular Journal. 2010;3:30-42.

13. Forbes JM, Cooper ME. Mechanisms of diabetic complications. Physiol Rev. 2013;93(1):137-88.

14. American Academy of Ophthalmology Retina Panel. Preferres Practice Pattern Guidelines: diabetic retinopathy. San Fransisco: American Academy of Ophthalmology; 2008 (4th printing 2012).

15. Sivaprasad S, Gupta B, Crosby-Nwaobi $R$, Evans J. Prevalence of diabetic retinopathy in various ethnic groups: a worldwide perspective. Surv Ophthalmol. 2012;57(4):347-70. 
16. Schubert HD. Retina and vitreous. In: Skuta GL, Cantor LB, Cioffi GA, editors. Basic and clinical science course. San Fransisco: American Academy of Ophthalmology; 2012. p. 738-79

17. Axer-Siegel R, Herscovici Z, Gabbay M, Mimouni K, Weinberger D, Gabbay U. The relationship between diabetic retinopathy, glycemic control, risk factor indicators and patient education.Isr Med Assoc J. 2006;8(8):523-6.

18. Pedersen ML. Management of type 2 diabetes mellitus in Greenland, 2008: examining the quality and organization of diabetes care. Int J Circumpolar Health. 2009;68(2):123-32.

19. Askew D, Schluter PJ, Spurling G, Maher CM, Cranstoun $P$, Kennedy $C$, et al. Diabetic retinopathy screening in general practice: a pilot study. Aust Fam Physician. 2009;38(8):650-6.

20. Andonegui J, Berástegui L, Serrano L, Eguzkiza A, Gaminde I, Aliseda D. Agreement among ophthalmologists and primary care physicians in the evaluation of retinographies of diabetic patients. Arch Soc Esp Oftalmol. 2008;83(9):527-31. 